\title{
Hydrocele of the canal of Nuck: ultrasound and MRI findings
}

\author{
This article was published in the following Dove Press journal: \\ Reports in Medical Imaging \\ II February 20I I \\ Number of times this article has been viewed
}

\author{
Edmund Soh' \\ Kenneth Sheah ${ }^{2}$ \\ Keh Oon Ong' \\ 'Department of Radiology, Singapore \\ General Hospital, Singapore; ${ }^{2}$ Radlink \\ Diagnostic Imaging, Paragon Medical, \\ Singapore
}

\begin{abstract}
Hydrocele (or cyst) of the canal of Nuck is rare and usually presents as a nontender groin mass. Imaging is useful in evaluation, and the diagnosis is suggested if a cystic lesion is found within the inguinal canal. We report the ultrasound and magnetic resonance imaging (MRI) findings of a hydrocele of the canal of Nuck, with MRI demonstrating a multiseptated cystic structure.
\end{abstract}

Keywords: inguinal region, hydroceles, ultrasound diagnosis

\section{Introduction}

The canal of Nuck is a small pouch of parietal peritoneum that accompanies the round ligament into the inguinal canal during female development. The entire canal normally becomes obliterated during the first year of life. A hydrocele (or cyst) of the canal of Nuck occurs from incomplete obliteration of the canal resulting in fluid becoming encysted within a remnant of the peritoneum. ${ }^{1,2}$ Such hydroceles have been described in the literature rarely. In particular, to our knowledge the limited magnetic resonance imaging (MRI) reports have described the lesion as a simple cyst.

\section{Case report}

A 39-year-old woman presented with a 1-month history of intermittent swelling in the right inguinal region. The patient was otherwise well. Physical examination was unremarkable with no convincing mass identified.

Ultrasound examination of the right inguinal region was performed using a Sequoia 12.0 system with an $8-15 \mathrm{MHz}$ linear array transducer (Siemens, Mountain View, $\mathrm{CA}$ ). This revealed a $4 \times 2 \times 1 \mathrm{~cm}$, tubular, anechoic lesion within the right inguinal canal medial to the right common femoral vessels. There was posterior acoustic enhancement with edge shadowing in keeping with a cystic lesion. No convincing septation could be identified at the time of the ultrasound examination. No internal or peripheral vascularity was demonstrated on color Doppler or power Doppler imaging (Figure 1). There was no change in lesion size or position with Valsalva maneuvers. No intraperitoneal communication was identified. The ultrasound diagnosis was a hydrocele of the canal of Nuck.

MRI was requested by the referring clinician to confirm the ultrasound findings. MRI demonstrated the lesion as a multiseptated cystic structure with rim enhancement and enhancement of the septae after intravenous contrast medium (Figure 2).

At surgery, the mass was excised. Pathological examination revealed a hydrocele of the canal of Nuck which was multiloculated and contained hemorrhagic fluid.
Correspondence: Edmund Soh Department of Diagnostic Radiology, Singapore General Hospital, Singapore 169608

$\mathrm{Tel}+6563266116$

Fax +65 63265242

Email esoh@doctors.org.uk submit your manuscript | www.dovepress.com

Dovepress

DOI: 10.2147/RMI.S17120
Reports in Medical Imaging 20II:4 I5-17

(C) 20II Soh et al, publisher and licensee Dove Medical Press Ltd. This is an Open Access article which permits unrestricted noncommercial use, provided the original work is properly cited. 

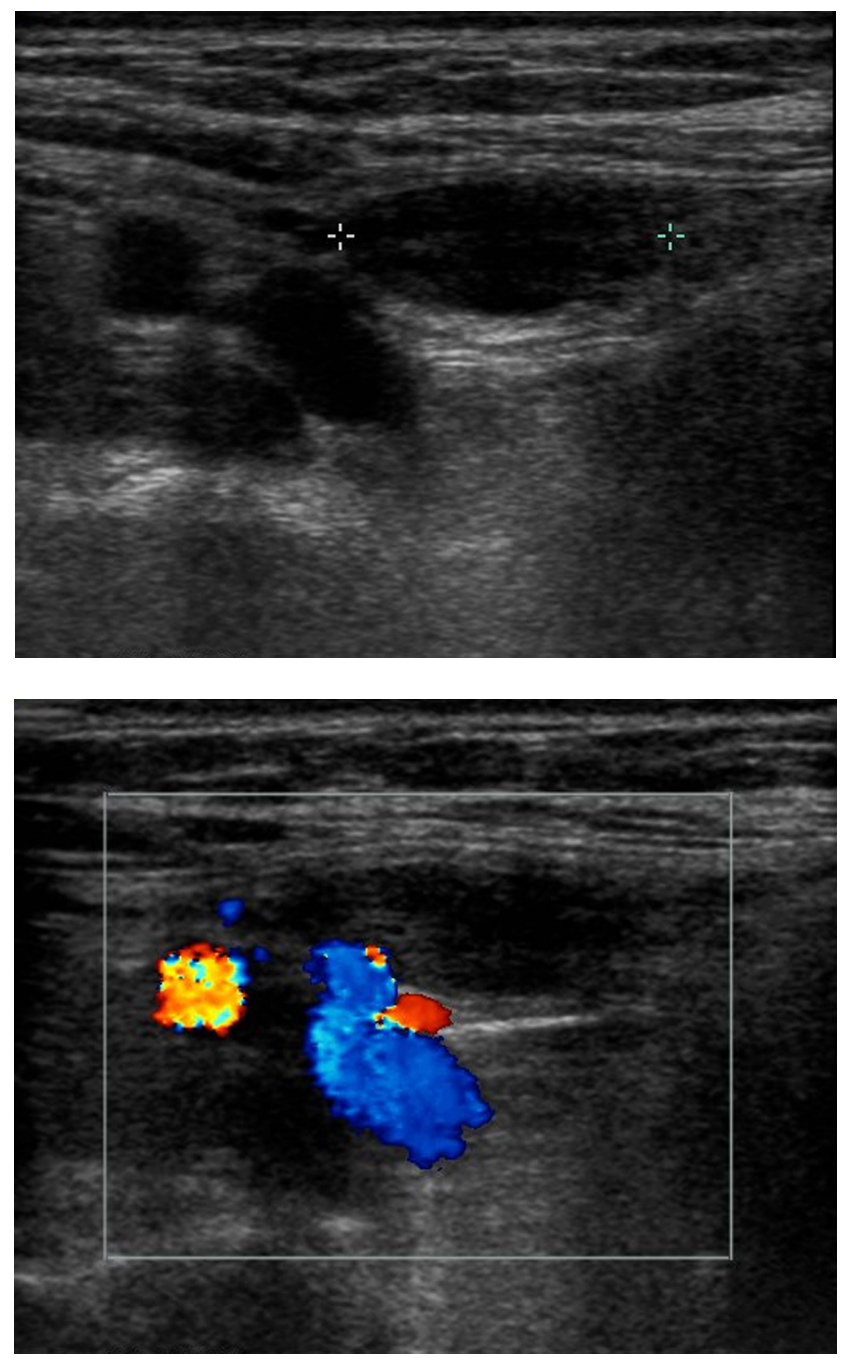

Figure I Ultrasound of the right inguinal region, grayscale A) and with color Doppler B) demonstrating a cystic lesion (between cursors) in the right inguinal canal, medial to the right femoral vessels.

\section{Discussion}

The canal of Nuck is a small protrusion of peritoneum that corresponds to the processus vaginalis in the male. A hydrocele of the canal of Nuck is a rare condition resulting from incomplete obliteration of the canal and entrapment of fluid. Clinically, it usually presents as a nontender mass or swelling in the inguinal region. ${ }^{3}$

The diagnosis of a hydrocele of the canal of Nuck is suggested by the finding of a cystic lesion in the inguinal canal. The cystic appearances have been described with ultrasound and MRI, the ultrasound appearances ranging from a "comma-shaped lesion with its tail directed toward the inguinal canal" to a "cyst-in-cyst" appearance to a multiseptated lesion. ${ }^{5}$ The limited reports of the MRI findings of hydroceles of the canal of Nuck, however, to our knowledge have not described septations, even when seen on ultrasound. ${ }^{6}$
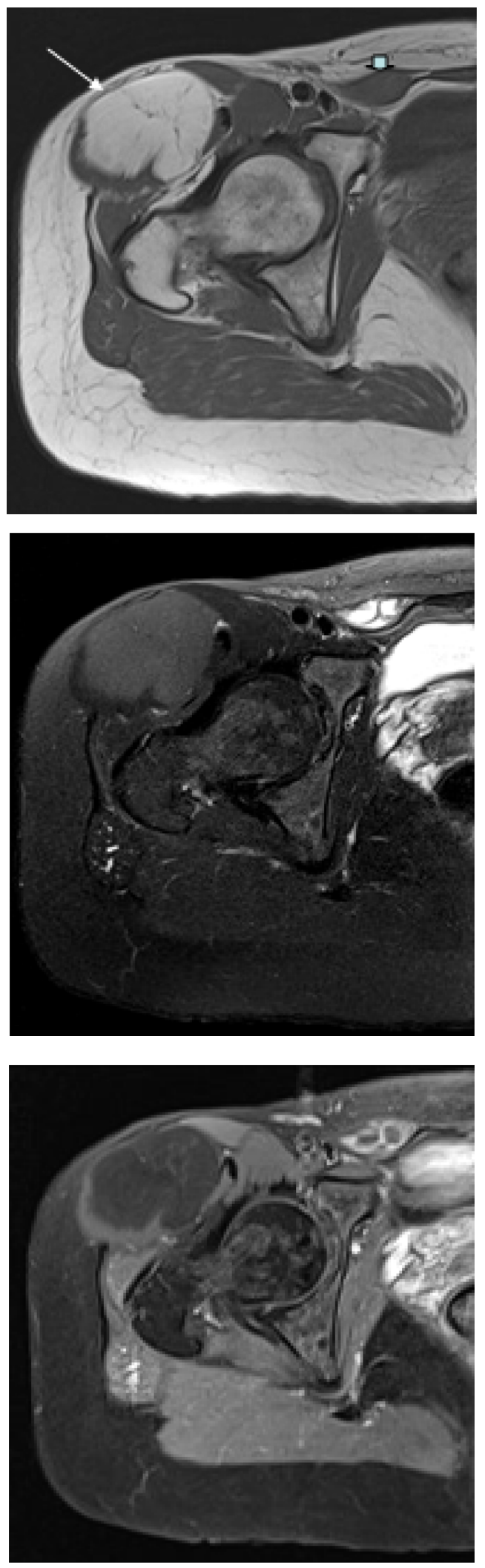

Figure 2 Axial MRI of the right inguinal region. The hydrocele of the canal of Nuck (short, blue arrow) is predominantly of low signal intensity on $T_{1} w$ and of high signal intensity on $\mathrm{T}_{2} \mathrm{w}$. The wall and septae enhance after intravenous gadolinium. Incidental finding of a lipoma (long, white arrow) within the right tensor fasciae latae muscle. A) $\mathrm{T}_{1}$-weighted image; B) $\mathrm{T}_{2}$-weighted image; C) Fat-suppressed $\mathrm{TI}$-weighted image after intravenous gadolinium. 
We describe septations which are clearly depicted on MRI and which enhance after intravenous contrast medium. These septations are in keeping with underlying inflammation and/or hemorrhage.

The most common differential of hydroceles of the canal of Nuck is the inguinal hernia, and both can coexist in about one-third of patients. The cystic nature of the lesion points towards a hydrocele of the canal of Nuck. ${ }^{7-9}$ Valsalva maneuvers with ultrasound visualization can also be used to help differentiation from hernias. ${ }^{6}$ Graded compression of the hydrocele has also been reported to open and distend a patent canal of Nuck. ${ }^{10}$ Other differentials include incarcerated hernias, abscesses, vascular abnormalities, and cystic-appearing tumors. Ultrasound usually resolves most of these with careful technique and application of color/power Doppler, and of course, correlation with the clinical presentation.

The authors would suggest that ultrasound is the first imaging modality of choice in the assessment of groin lesions. Ultrasound is cheap, readily available, and allows dynamic assessment. MRI is suggested as a problemsolving tool.

In conclusion, a cystic lesion in the female inguinal canal is suggestive of a hydrocele of the canal of Nuck. Valsalva maneuvers can be used to help confirm the diagnosis. We describe MRI findings of internal septations which were not demonstrated on initial ultrasound.

\section{Disclosure}

The authors report no conflicts of interest in this work.

\section{References}

1. Shadbolt CL, Heinze SB, Dietrich RB. Imaging of groin masses: inguinal anatomy and pathologic conditions revisited. Radiographics. 2001;21:S261-S271.

2. Stickel WH, Manner M. Female hydrocele (cyst of the canal of Nuck): sonographic appearance of a rare and little-known disorder. J Ultrasound Med. 2004;23:429-432.

3. Khanna PC, Ponsky T, Zagol B, Lukish JR, Markle BM. Sonographic appearance of canal of Nuck hydrocele. Pediatr Radiol. 2007;37: 603-606.

4. Park SJ, Lee HK, Hong HS, et al. Hydrocele of the canal of Nuck in a girl: ultrasound and MR appearance. Br J Radiol. 2004;77(915):243-244.

5. Miklos JR, Karram MM, Silver E, Reid R. Ultrasound and hookwire needle placement for localization of a hydrocele of the canal of Nuck. Obstet Gynecol. 1995;85(5):884-886.

6. Safak AA, Erdogmus B, Yazici B, Gokgoz AT. Hydrocele of the canal of Nuck: sonographic and MRI appearances. J Clin Ultrasound. 2007;35(9):531-532.

7. Chandrasekharan LV, Rajagopal AS. The hydrocele of the canal of Nuck: an ultrasound diagnosis. Internet J Radiol. 2006;4:2. http://www. ispub.com/ostia/index.php?xmlFilePath=journals/ijra/vol4n2/nuck.xml. Accessed January 15, 2011.

8. Huang CS, Luo CC, Chao HC, Chu SM, Yu YJ, Yen JB. The presentation of asymptomatic palpable movable mass in female inguinal hernia Eur J Pediatr. 2003;162:493-495.

9. De Meulder F, Wojciechowski M, Hubens G, Ramet J. Female hydrocele of the canal of Nuck: a case report. Eur J Pediatr. 2006;165: 193-194.

10. Yigit H, Tuncbilek I, Fitoz S, Yigit N, Kosar U, Karabulut B. Cyst of the canal of Nuck with demonstration of the proximal canal: the role of the compression technique in sonographic diagnosis. J Ultrasound Med. 2006;25:123-125.
Reports in Medical Imaging

\section{Publish your work in this journal}

Reports in Medical Imaging is an international, peer-reviewed, open access journal publishing original research, reports, reviews and commentaries on all areas of medical imaging. The manuscript management system is completely online and includes a very quick and fair peer-review system, which is all easy to use.

\section{Dovepress}

Visit http://www.dovepress.com/testimonials.php to read real quotes from published authors. 